\title{
Coordination mechanism of SaaS service supply chain: Based on compensation contracts
}

\author{
Yanli Guo ${ }^{1}$, Jianbin Chen ${ }^{1}$, Hailing $\mathrm{Guo}^{2}$, Xinman $\mathrm{Lu}^{2}$ \\ ${ }^{1}$ Business College of Beijing Union University (China) \\ ${ }^{2}$ Business School of Nankai University (China) \\ yanli.gu@@buu.edu.cn,jianbin.chen@,buu.edu.cn,guohailing@nankai.edu.cn, luxinman@nankai.edu.cn
}

\section{Abstrad:}

Purpose The purpose of this paper is to build new contracts theories of SaaS service supply chain. Software as a Service (SaaS) has become a hot topic in this industry. Compared with traditional manufacturing supply chain and general service supply chain, the new IT service supply chain which based on SaaS has characteristics of both service and IT. And SaaS is completely different from traditional software package model. Therefore the classic contracts, which be widely used in traditional manufacturing supply chain, can't be directly applied in SaaS service supply chain. The necessary way of IT services developing is to study the SaaS service supply chain combining with characteristics of SaaS. Therefore, It focuses on the coordination of SaaS service supply chain.

Design/methodlogy/approadr It tries to answer the following question: how do the ISV motivate SaaS operators to improve the service level through effective contracts mechanism under conditions of asymmetric information. In order to answer these questions, this paper does some researches including: Under the conditions of information asymmetry, supposing the service level (is related to the degree of effort) of SaaS operator was private information, we construct model of compensation contract, i.e., to motivate SaaS operator to improve service level through transfer payments of compensation price. 
Findings and originality/value The study finds out that when ISV get to "positive feedback", instead of the traditional market equilibrium, compensation contract (linear) can coordinate satisfactorily the SaaS service supply chain. In the point of "positive feedback", the marginal revenue equals the marginal cost, but it is not the equilibrium of ISV'profit-maximization.

Research limitations/implications: There are some limitations in this research. In the linear compensation contracts, the compensation price is fixed value. If in the contract, we can create a change value which is related to the sales volume of service, the coordination efficiency of compensation will be increased. And in the future, the nonlinear compensation contracts should be researched.

Practical implications: In the practical implication, it will promote the development of study and practice of SaaS and IT service industry. And it is beneficial to ISV, platform operators and customers.

Originality/value From the theoretical perspective, this paper put forward some new contracts and motivating mechanism for effective coordination of SaaS service supply chain and the conclusion will enrich content of service supply chain theory system. In theory, it has more significance for further researching on SaaS and service supply chain.

Keyword: SaaS (Software as a Service), service supply chain, compensation contracts, coordination, the cervice level, positive feedback

\section{Introduction}

The service level is the key of service supply chain coordinating. The SaaS service supply chain is no exception. It is a new arena which has attracted the attention of academic circles. Some scholars have done few researches about SaaS and SaaS supply chain, such as coordination strategies of SaaS supply chain (Demirkan, Cheng \& Bandyopadhyay, 2010), contracts for software or services (Dey, Fan \& Zhang, 2009; Roels, Karmarkar \& Carr, 2010), competition between Shrink-Wrap software and SaaS(Fan, Kumar \& Whinston, 2009) and other topics related to SaaS (Susarla, Barua \& Whinston, 2010). However, there are still a large research space, especially in the coordination contracts of SaaS service supply chain (Yan, Guo \& Schatzberg, 2012).

In traditional manufacturing supply chain, the upstream manufacturers are unable to accurately obtain sales information from the downstream retailers because of information asymmetry (Zhang, Liu, Wu \& Jiao, 2010). Therefore they motivate retailers to increase the 
number of orders by repurchasing surplus products (Cachon \& Lariviere, 2001; Van Donselaar, Gaur, Van Woensel, Broekmeulen \& Fransoo, 2010). But for perishable goods, as we know, the buyback quantities the less the better either to manufacturers or distributors. Tsay (2001) reports that retailers often use "price compensation" to reduce the buyback quantities in industries. The service ability can not be stored, which leads to the limitation of buyback contracts application, but "price compensation" has a good applicability for the coordination of the service ability. There are few literatures (Shao \& Ji, 2008; Yan, 2010; Arie \& Grieco, 2012) have applied Compensation contracts in the service plan of supply chain. In the Compensation contracts, one party motivates the other to increase sales or improve investment of service by a certain amount of price compensation in a supply chain.

In SaaS service supply chain, online service delivery is the main value-added chain (Concha, Espadas, Romero \& Molina, 2010; Katzmarzik, 2011). Because software service can't be stored or exchanged (Mathew \& Nair, 2010), buyback contract will not work. The software service has the common features which are different between general service and products (Mietzner, Leymann \& Unger, 2011), and "price compensation" can also be applied. ISVs can motive SaaS operators to improve the service level, to expand market sales and increase customer satisfaction through a certain amount of "price compensation".

In reality, lots of SaaS operators often need to increase input on network security operation in order to guarantee the quality of service and avoid the risk loss caused by service quality problems, such as service disruption. In addition, they also need ISVs to ensure the quality and quantity of service to meet online customer demands. Owing to that when singing the contract, SaaS operators request for submission of security fees from ISVs, such as Salesforce.com, or risk margin system of Alisoft.

Salesforce.com has a detailed ISVs Partner Program. In this program, Salesforce.com has developed a detailed ISV service security fee system. Although Salesforce.com does not charge ISVs for technical service fee, ISVs which join the partner program need to pay a certain amount of security costs, or they can't use online service platform AppExchange and other services of Salesforce.com.

The Alisoft's risk margin is no less than 5000 RMB in technical service charging standards, which is used for compensation funds to guarantee the service level. ISVs should pay a certain amount of money according to the consumer security service details, which provides consumers with the security service after they order ISVs' products releasing on the Alisoft platform. Risk margin should be deposited and frozen in ISVs' Alipay account. After ISVs sign the Alisoft platform cooperation agreement, Alisoft can instruct Alipay to freeze the corresponding amount payment of the Alipay account as risk margin. Alipay has a right to notify ISVs to adjust the amount of margin by written notice (including but not limited to email, fax) according to ISVs' business change and the actual compensation. If ISVs fail to 
complement the risk margin of their Alipay account after receiving the notice for ten days, Alisoft has the right to immediately suspend or terminate the cooperation agreements. And ISVs needn't pay for technical service fee to Alisoft (www. Alisoft.com) besides the 5000 RMB risk margin. Thus, the risk of SaaS operators has got certain guarantee when they face with large events such as service interrupt, and risk margin ensures consumers can get compensation in time.

Therefore, this paper will build a Compensation contract mechanism based on the above analysis and realistic foundation. We will set service security fee as a contract parameter, compensating price as a decision variable of ISVs and service level as a decision variable of SaaS operators.

\section{The Problem Description and Basic Model}

we consider a two-stage supply chain which is composed of an ISV (Independent Software Vendors)and a SaaS operator.

Only a single kind of service and a single sales cycle be considered, and it is supposed that in a single sales cycle, $q$ is the capability of service providing of SaaS operators. That's to say, the effective demand will be bigger than zero and less than $q$.

- $p$ : The rent of unit service,

- $\pi_{i}$ : Revenue function of ISV,

- $\pi_{s}$ : Revenue function of SaaS platform operator,

- $C_{s}$ : Fixed costs of platform operator in a single sales cycle,

- $C_{o s}$ : Variable costs of platform operator(measure by time, the variable costs of monthly service),

- $C_{i}$ : Fixed costs of ISV in a single sales cycle,

- $C_{o i}$ : Variable costs of ISV for unit service (measure by month), $C_{o s}+C_{o i}<p$;

The demand of market for online software service is a random variable $D(p)$, which is related

to the price. Its distribution function is $F(x, p)(x>0)$, density function is $f(x, p)$. And $\frac{\partial f(x, p)}{\partial p}$ exist and is not equal to zero.

It is supposed that the service level is a continuous variable $(\mu)$ which is related to the degree of effort. The SaaS operator has to pay a certain costs in order to improve the service level 
and service level is higher, the higher the cost. The cost function of the SaaS operator under the appropriate service can be written as (Zhang, 1996; Laffont \& Martimort, 2002):

$$
C(u)=\frac{1}{2} a \mu^{2}, \text { constant } a>0 .
$$

The sales volume of Service is $Q=\varepsilon \mu+\theta, \varepsilon$ is output coefficient $(\varepsilon>0)$, and $\theta$ is market random factors.

We build a basic model of Compensation contract based on unlimited service capability $(q \rightarrow \infty)$. First, the ISV pays a certain amount of service security fees to the SaaS operator, such as Salesforce.com. And then It pay a certain amount of compensation prices to incentive SaaS operator to choose the service level good for the ISV (see Figure 1).

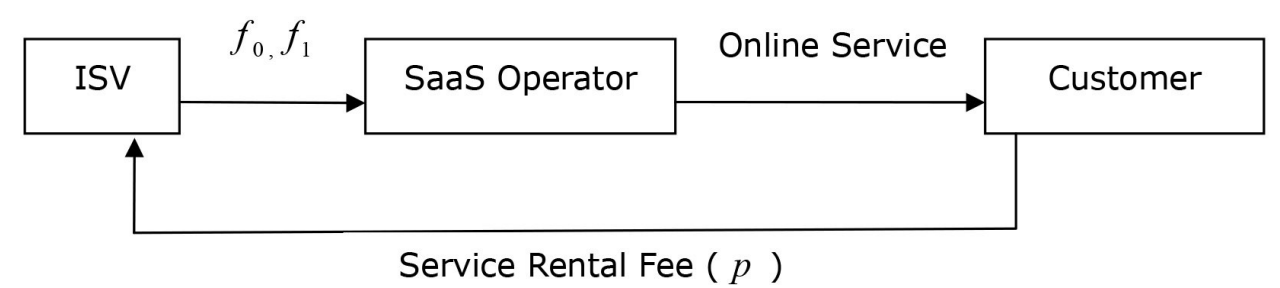

Figure 1. The Basic Model of Compensation Contract

We suppose the service security fee is $f_{0}$, the unit compensation price is $f_{1}$, and $0<f_{0}<p$.

In a centralized supply chain two parties have a unified decision-making process, but in a decentralized supply chain the ISV and the SaaS operator make the decision respectively, and the sequence of decision is as follows:

- Both parties determine contract parameter $\left(f_{0}\right)$, which is service security fee,

- The ISV determines the best compensation price $\left(f_{l}\right)$ based on $f_{0,}$

- The SaaS operator observes the ISV's decision of $f_{l}$, then makes the decision on service level $(\mu)$ to maximize its own interest considering contract parameter $\left(f_{0}\right)$.

Service capability is unlimited $(q \rightarrow \infty)$, therefore in the basic model the cost of service-delaying does not exist.

In centralized supply chain, the target function maximizing the joint profits of supply chain can be expressed as:

$$
\begin{gathered}
\max _{\mu} \pi(p, u)=p Q(\mu)-C_{T}-\left(C_{0 i}+C_{0 s}\right) \cdot Q(\mu)-\frac{1}{2} a \mu^{2}, \text { here } C_{T}=C_{i}+C_{s} \\
\frac{\partial \pi}{\partial \mu}=\left(p-C_{0 i}+C_{0 s}\right) \cdot \varepsilon-a \mu \quad \frac{\partial^{2} \pi}{\partial \pi^{2}}<0,
\end{gathered}
$$


Therefore a maximum value exists.

Let $\frac{\partial \pi}{\partial \mu}=0$, the optimal service level is given by $\mu^{*}=\frac{\varepsilon \cdot\left(p-C_{0 i}-C_{0 s}\right)}{a}$

The service level is the reaction function of market service rent $(p)$. It is a parameter determined by the market in Compensation contract, rather than a decision variable.

In decentralized supply chain, the target function of ISV can be written as:

$$
\max _{f_{1}} \pi_{i}\left(f_{1}, \mu\right)=\left(p-f_{1}\right) Q(\mu)-f_{0}-C_{i}-C_{0 i} \cdot Q(\mu)
$$

The target function of SaaS operator can be written as:

$$
\max _{\mu} \pi_{s}\left(f_{1}, \mu\right)=f_{1} \cdot Q(\mu)+f_{0}-C_{s}-C_{0 s} \cdot Q(\mu)-\frac{1}{2} a \mu^{2}
$$

It is supposed that the service level of the operator is not stable, when the operator's service level can meet the market demands, then the ISV pays the compensation price. If the service demands can not be fulfilled, for example service delaying, the ISV will not pay it.

\section{The Coordination under Linear Compensation Contract}

When the demand is less than the maximum market capacity which SaaS operator supplies $q$ (Service capacity), the market demand will always be met. Which means that when the service capacity is unlimited, namely, $Q<q$, we established the linear Compensation contract , setting the Compensation price as the independent decision variable. If SaaS operator can supply services to meet all the market demands, then the ISV will give the SaaS operator a fixed Compensation price per unit $f_{l}$. However if the SaaS operators can't provide the required service level, then they will not get the compensation. That is, when the market demand exceeds the maximum market capacity, the supply chain may incur the service outage or service delay, ISV will not pay the SaaS operator the Compensation price. Therefore, the Compensation contract model is established basing on the hypothesis of the service capacity unlimited. There is the basic model, as shown in Figure 1.

\subsection{Independent decision of SaaS operator and ISV in decentralized supply chain}

Based on basic model, The objective function of SaaS operator is that:

$$
\begin{gathered}
\max _{\mu} \pi_{s}\left(f_{1}, \mu\right)=f_{1} \cdot Q(\mu)+f_{0}-C_{s}-C_{0 s} \cdot Q(\mu)-\frac{1}{2} \alpha \mu^{2} \\
\frac{\partial \pi_{s}}{\partial \mu}=\varepsilon\left(f_{1}-C_{0 s}\right)-\alpha \mu
\end{gathered}
$$


Solving the first-order condition for the optimal service level by maximizing the profit function, we obtain the following service level:

$$
\mu_{s 1}^{*}=\frac{\varepsilon}{\alpha}\left(f_{1}^{*}-C_{0 s}\right)
$$

The service level is the reaction function of compensation price, $\frac{\partial \mu^{*}\left(f_{1}\right)}{\partial f_{1}}=\frac{\varepsilon}{\alpha}>0$, so the service level set by the SaaS operator is increasing in the compensation price given by ISV. From the decision-making order and the expression of the optimal service level, we can find that the optimal decision of SaaS operator depends on the compensation price decision of ISV. After substituting the optimal service level (see it formula 2) into the ISV's profit function $\max _{f_{1}} \pi_{i}\left(f_{1}, \mu_{s l}^{*}\right)$, the first-order condition for ISV's maximization problem gives the following compensation price for ISV:

$$
f_{1}^{*}=\frac{p+C_{0 s}-C_{0 i}}{2}
$$

Theorem 1: In the case of service capacity unlimited $(Q<q)$, by using the linear compensation contract, we get the optimal service level of centralization decision-making as: $\frac{\varepsilon \cdot\left(p-C_{0 i}-C_{0 s}\right)}{a} ;$ the optimal service level of decentralization decision-making as: $\frac{\varepsilon}{a}\left(f_{1}-C_{0 s}\right)$

\subsection{The comparison of service level between the decentralization decision-making and centralization decision-making}

In the case of service capacity unlimited, the service level of the centralization decision-making is shown in Theorem 1. Obviously, when $0<f_{l}<p-C_{0 i}$, there exists $\mu_{s l}{ }^{*}<\mu^{*}$ and if $p>f_{l}>p-C_{0 i}$ there exists $\mu_{s l}{ }^{*}>\mu^{*}$ if $f_{l}=p-C_{0 i}$, then $\mu_{s l}{ }^{*}=\mu^{*}$. That is, when the ISV's marginal revenue equals the marginal cost, it can coordinate the supply chain. When the compensation price $\left(f_{l}\right)$ is lower than the difference between the market service price $(p)$ and the ISV's variable costs $\left(C_{0 i}\right)$ the SaaS operator's service level in decentralization decision-making is lower than the service level in centralization decision-making. While when the compensation price $\left(f_{l}\right)$ is higher than the difference between the market service price $(p)$ and the ISV's variable cost $\left(C_{0 i}\right)$, there are higher decision efficiency in the decentralization supply chain than in the centralization supply chain. However, in fact, this perfect result is absolutely impossible, because when the marginal revenue of ISV is less than the marginal cost, it is diseconomies of scale for ISV. No change in the market price, ISV will reduce the compensation price to ensure self-interest maximization. 
Theorem 2: In the case of service capacity unlimited $(Q<q)$, ISV pays a fixed compensation price per unit to the SaaS operator, which form a linear compensation contract. When the marginal revenue of ISV equals the marginal cost, namely, $p=f_{l}+C_{0 i}$, the contract can make the supply chain effective coordination.

From the above theorem, we can see that in the linear compensation contract, the effective coordination of SaaS service supply chain depends on whether the compensation price can meet the restraint that the marginal revenue equals the marginal cost, that is $p=f_{l}+C_{0 i}$.

When the compensation price meet the optimal coordination conditions $p=f_{l}+C_{0 i}$, the optimal service level of SaaS operator equals to the optimal service level of centralization decisionmaking:

$$
\mu_{s 1}^{*}=\frac{\varepsilon}{\alpha}\left(f_{1}-C_{0 s}\right)=\frac{\varepsilon}{\alpha}\left(p-C_{0 s}-C_{0 i}\right)
$$

When ISV selects the optimal compensation price, we get SaaS operator's optimal service level as:

$$
\mu_{s l}^{*}=\frac{\varepsilon}{\alpha}\left(f_{1}-C_{0 s}\right)=\frac{\varepsilon}{2 \alpha}\left(p-C_{0 s}-C_{0 i}\right)
$$

The service level of SaaS operator improves when the supply chain achieves effective coordination, which proves the linear compensation contract is conductive to improve the quality of service. However, when the supply chain achieves effective coordination, the decision-making to the compensation price of ISV is not their optimal decision of maximizing self-interest. By comparing $f_{1}=p-C_{0 i}$ to $f_{1}^{*}$, we find that:

$$
\left(p-C_{0 i}\right)-f_{1}^{*}=\frac{p-C_{0 i}-C_{0 s}}{2}>0
$$

That means the compensation price of achieving the optimal coordination of the supply chain is greater than ISV's compensation price of independent decision-making. ISV needs to increase compensation price, if he wants to inspire SaaS operator to improve the service level, making the supply chain achieve optimal coordination. And the improvement in compensation price makes the revenue of ISV decrease, so when achieving effective coordination in supply chain, ISV's revenue is lower than the highest revenue, which will result in a loss of revenues. These losses of revenues transfer payment to SaaS operator through compensation price, and then ensure the improvement of the service level of SaaS operator.

\section{Discussion and Implication}

In the traditional economic, there is a law of diminishing marginal returns, marginal revenue equals marginal cost is the equilibrium of profit-maximization. But the study finds that in the SaaS service supply chain, the point where the marginal revenue equals the marginal cost is not the equilibrium of ISV'profit-maximization. 
As the above comparison between the decentralization decision-making and centralization decision-making shows that ISV's compensation price deviates from its optimal compensation price of profit-maximization, when achieving the optimal coordination of supply chain. The results are not consistent with the economic interpretation about marginal revenue equals marginal cost in traditional economics.

Market equilibrium theory in traditional economics is based on the assumption that the marginal utility decreases and the marginal cost increases (as shown in Figure 2a).As production increases, marginal revenue diminishes, and marginal cost increases. When marginal revenue is greater than the marginal cost, the total revenues increase as production increases; when marginal revenue is lower than the marginal cost, the total revenues decrease as production increases. The equilibrium of revenues maximization is the intersection of marginal benefit and marginal cost.

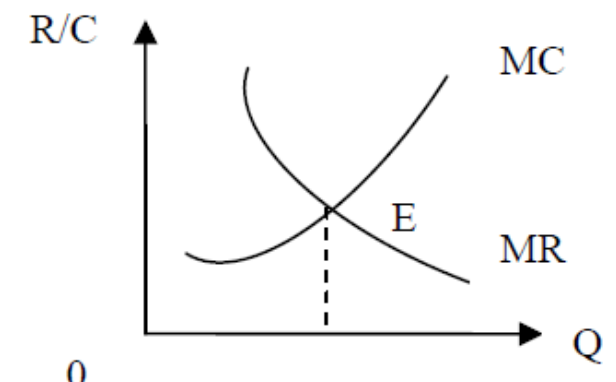

0

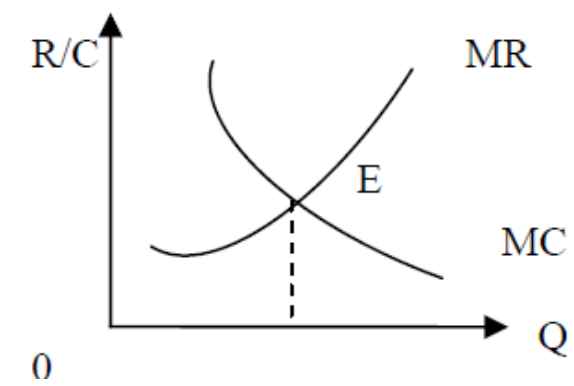

0

Figure 2. The traditional market equilibrium and the positive feedback of software market. (a) The traditional market equilibrium (b) The positive feedback of software market.

According to the theory of William Brian Arthur, the increase of the marginal revenue will lead to positive feedback, appearing many possible equilibrium in economy. When the increasing marginal revenue curve intersects the marginal cost curve, the phenomenon of positive feedback will be shown in the software market, which is "the strong will be stronger, and the weak will be weaker"(Sheng, 2009).

Based on the network economy theory, there is the law of increasing marginal returns, and a positive feedback phenomenon in software product market, resulting in the point where marginal revenue equals marginal cost is no longer the market equilibrium point (as shown in Figure $2 b$ ). The marginal revenue increases with the demand increasing, the marginal cost decreases with the demand increasing, and the positive feedback (Sheng, 2009) point is where marginal revenue equals the marginal cost. When the market demand is on the left side of the positive feedback point where the marginal revenue is less than the marginal cost, the company suffers losses; when the market demand is on the right of the positive feedback where the marginal revenue is greater than the marginal cost, the company gets profits, and the marginal profit will increase as the demand increasing. Therefore, through analysis of the conditions of effective coordination of SaaS service supply chain in compensation contract, that 
is $f_{1}=p-C_{0 i}$, we can find that the point which achieves the effective coordination of the supply chain in compensation contract is the positive feedback point of ISV market instead of the traditional market equilibrium.

Positive feedback theory can better explain the development patterns in network economic that companies must invest a large before getting profits. Many network enterprises have a relatively long input phase, and the harvest of benefits need to wait for the breakthrough of positive feedback point in the market. Because of the network effect, the company's marginal profit will increase rapidly, once entering the state of profitability. At the same time, the law of diminishing marginal cost can also explain the acceptable market price of network products will decline rapidly with the expansion of the business scale. Especially, as the expansion of the market scale, the phenomenon of price reduction is universal in the products which have the network feature such as software products and electronic products (Yuan \& Han, 2011), SaaS is no exception. With the propelling of the positive feedback mechanism, the rental price of SaaS service will diminish gradually as the decreasing of marginal cost, and its profit will go up rapidly with the increase of the demand.

\section{Conclusion}

Software as a Service (SaaS) has become a hot topic in industry of information technology and will be the mainstream model of IT services delivering. Compared with traditional manufacturing supply chain and general service supply chain, in the field of SaaS service supply chain, there are many mew topic which need to be discussed using new methods and theories from a new perspective. Therefore the classic contracts, which be widely used in traditional manufacturing supply chain, can't be directly applied in SaaS service supply chain. This paper focuses on the coordination of SaaS service supply chain, has build a new model of compensation contract, which be used to discussed how do the ISV motivate SaaS operators to improve the service level through effective contracts mechanism under conditions of asymmetric information.

In this paper, considering information asymmetry, it is supposed the service level (which is related to the degree of effort) of SaaS operator was private information, and the model of compensation contract has been constructed, i.e., to motivate SaaS operator to improve service level through transfer payments of compensation price. A new found is that there are a positive feedback phenomenon in the SaaS market, that is the point where marginal revenue equals marginal cost. And it is interesting that is no longer the market equilibrium point such as the traditional economic said. But it is a point on the right of where the marginal revenue will increase as the demand increasing. And It is found that when ISV get to "positive feedback", the linear compensation contract can coordinate the SaaS service supply chain well.

The subject of this paper fully caters to the needs of industry development, is frontier of theoretical study and industry development. This paper put forward some contracts and 
motivating mechanism for effective coordination of SaaS service supply chain and the conclusion will enrich content of service supply chain theory system and promote the development of study and practice of SaaS and IT service industry.

There are several theoretical and practical implications. In theory, it has more significance for further researching on SaaS and service supply chain. And in practice, it is beneficial to ISV, platform operators and customers. And some effective contract models are the key of the development of IT service industries.

In additional, there are some limitation of linear compensation contracts. In the linear compensation, the compensation price is fixed value. If in the contract, we can create a change value which is related to the sales volume of service, the coordination efficiency of compensation will be increased.

In the future, there are many researches we will do. At first, in this paper only the basic model and the linear model has been build. In the future, in order to resolving more practical problems, the nonlinear compensation contracts should be researched. And second, we try to relax some assumptions, such as service types and sales cycle. In addition, platform operators change information asymmetry in supply chain and contract mechanism under different states of information symmetry or asymmetry should be researched in future. Another important thing is that in this paper we discuss coordination efficiency of compensation contract for SaaS service supply chain based on the hypothesis of the service capacity $(q)$ unlimited. In the future, the condition that the market demand exceeds the maximum market capacity, that is, service delaying should be concerned.

\section{Acknowledgments}

The authors gratefully acknowledge the Funding Project for Academic Human Resources Development in Institutions of Higher Learning Under the Jurisdiction of Beijing Municipality (No. PHR201108389), the Project for the Beijing excellent talents (No.2012D005022000004), the Funding of research plan from the education committee of Beijing (SQSM201211417002) and the Funding project of Beijing Philosophy and Social Science Research Program (11JGB039).

\section{References}

Arie, G., \& Grieco, P.L.E. (2012). Do Firms Compensate Switching Consumers? Simon School Working Paper, No. FR 12-13. Available at SSRN: http://ssrn.com/abstract $=1802675$

Cachon, G.P., \& Lariviere, M.A. (2001). Contracting to Assure Supply: How to Share Demand Forecasts in A Supply Chain. Management Science, 47(5), 629-646. http://dx.doi.org/10.1287/mnsc.47.5.629.10486 
Concha, D., Espadas, J., Romero, D., \& Molina, A. (2010). The e-HUB evolution: From a Custom Software Architecture to a Software-as-a-Service implementation. Computers in Industry, 61(2), 145-151. http://dx.doi.org/10.1016/j.compind.2009.10.010

Demirkan, H., Cheng, H.K., \& Bandyopadhyay, S. (2010). Coordination Strategies in an Saas Supply Chain. Journal of Management Information Systems, 26(4), 119-143. http://dx.doi.org/10.2753/MIS0742-1222260405

Dey, D., Fan, M., \& Zhang, C. (2009). Design and Analysis of Contracts for Software Outsourcing. Information Systems Research Articles in Advance, 1-22.

Fan, M., Kumar, S., \& Whinston, A.B. (2009). Short-Term and Long-Term Competition between Providers of Shrink-Wrap Software and Software as a Service. European Journal of Operational Research, 196(2), 661-671. http://dx.doi.org/10.1016/j.ejor.2008.04.023

Katzmarzik, A. (2011). Product Differentiation for Software-as-a-Service Providers. Business \& Information Systems Engineering, 3(1), 19-31. http://dx.doi.org/10.1007/s12599-010-0142-4

Laffont, J.J., \& Martimort, D. (2002). Incentive theory (Vol.1): the principal-agent model. Beijing: Renmin University of China press.

Mathew, M., \& Nair, S. (2010). Pricing Saas Models: Perceptions of Business Service Providers and Clients. Journal of Services Research, 10(1), 51-68.

Mietzner, R., Leymann, F., \& Unger, T. (2011). Horizontal and vertical combination of multitenancy patterns in service-oriented applications. Enterprise Information Systems, 5(1), 59-77. http://dx.doi.org/10.1080/17517575.2010.492950

Roels, G., Karmarkar, U.S., \& Carr, S. (2010). Contracting for Collaborative Services. Management Science, 56(5), 849-863. http://dx.doi.org/10.1287/mnsc.1100.1146

Susarla, A., Barua, A., \& Whinston, A.B. (2010). Multitask Agency, Modular Architecture, and Task Disaggregation in Saas. Journal of Management Information Systems, 26(4), 87-117. http://dx.doi.org/10.2753/MIS0742-1222260404

Shao X., \& Ji, J. (2008). Research on coordination between supply chain pricing and capacity design based on compensation contract. Chinese Journal of Management Science, 16(4), 62-68.

Sheng X. (2009). Network Economics[M]. Beijing: Publishing House of electronics industry.

Tsay, A.A. (2001). Managing retail channel overstock: Markdown money and return policies. Journal of Retailing, 77(4), 451-492. http://dx.doi.org/10.1016/S0022-4359(01)00055-0 
Van Donselaar, K.H., Gaur, V., Van Woensel, T., Broekmeulen, R.A., \& Fransoo, J.C. (2010). Ordering Behavior in Retail Stores and Implications for Automated Replenishment. Management Science, 56(5), 766-784. http://dx.doi.org/10.1287/mnsc.1090.1141

Yan C. (2010). The capacity coordination of service outsourcing supply chain under compensation contract. Journal of Fujian Agriculture and Forestry University (Philosophy and Social Sciences), 13(5), 70-73.

Yan, J., Guo, Y., \& Schatzberg, L. (2012). Coordination Mechanism of IT Service Supply Chain: An Economic Perspective. Electronic Markets, 22(2), 95-103. http://dx.doi.org/10.1007/s12525012-0086-2

Yuan, H., \& Han, S. (2011). The Effects of Consumers' Price Expectations on Sellers' Dynamic Pricing Strategies. Journal of Marketing Research (JMR), 48(1), 48-61. http://dx.doi.org/10.1509/jmkr.48.1.48

Zhang W. (1996). Game Theory and Information Economics. Shanghai: Shanghai people's Publishing House.

Zhang, Y., Liu, S.J., Wu, L., \& Jiao, Y.C. (2010). Service-oriented Enterprise Interoperability in Automobile Supply Chain Management. Computer Science and Information Systems, 7(1), 31-49. http://dx.doi.org/10.2298/CSIS1001031Z

\section{Appendix}

Proof of Formula 3

The objective function as follows:

$$
\max _{f_{1}} \pi_{i}\left(f_{1}, \mu^{*}\right)=\left(p-f_{1}\right) \cdot Q\left(\mu^{*}\right)-f_{0}-C_{i}-C_{0 i} \cdot Q\left(\mu^{*}\right)
$$

The optimal service level of SaaS operator is (Formula 2): $\mu_{s l}^{*}=\frac{\varepsilon}{a}\left(f_{1}-C_{0 s}\right)$;

The market demands is $Q=\varepsilon \mu+\theta$;

Solving the first-order condition for the compensation price, we obtain:

$$
\begin{gathered}
\frac{\partial \pi_{i}}{\partial f_{1}}=-\left[\frac{\varepsilon^{2}}{a}\left(f_{1}-C_{0 s}\right)+\theta\right]+\left(p-f_{1}\right) \cdot \frac{\varepsilon^{2}}{a}-\frac{\varepsilon^{2}}{a} C_{0 i} \\
=-\frac{2 \varepsilon^{2}}{a} f_{1}+\frac{\varepsilon^{2}}{a}\left(p+C_{0 s}-C_{0 i}\right)-\theta
\end{gathered}
$$

$\frac{\partial^{2} \pi_{i}}{\partial f_{1}^{2}}=-\frac{2 \varepsilon^{2}}{a}<0$, the optimum exists. 
Let $\frac{\partial \pi_{i}}{\partial f_{1}}=0$, get,

$$
f_{1}^{*}=\frac{p+C_{0 s}-C_{0 i}-\theta \cdot \frac{a}{\varepsilon^{2}}}{2}
$$

Because $\theta$ is market random factor, the optimal compensation price can be written as:

$$
f_{1}^{*}=\frac{p+C_{0 s}-C_{0 i}-\theta}{2}
$$

Without considering $\theta$, the optimal compensation price of ISV can be written as:

$$
f_{1}^{*}=\frac{p+C_{0 s}-C_{0 i}}{2}(\text { Formula } 3)
$$

Q.E.D

Journal of Industrial Engineering and Management, 2013 (www.jiem.org)

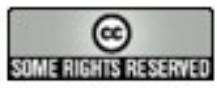

Article's contents are provided on a Attribution-Non Commercial 3.0 Creative commons license. Readers are allowed to copy, distribute and communicate article's contents, provided the author's and Journal of Industrial Engineering and Management's names are included. It must not be used for commercial purposes. To see the complete license contents, please visit http://creativecommons.org/licenses/by-nc/3.0/. 